\title{
Property Valuation Challenges for Properties Condemned for Environmental Public Upgrades
}

\author{
Odysseas Kopsidas \\ Technological Educational Institute of Thessaloniki, Thessaloniki, Greece \\ Leonidas Fragkos-Livanios \\ Hellenic Army Academy, Attiki, Greece
}

\begin{abstract}
No property may be taken for public use without just compensation. The issue is what is "just compensation" and how it is determined in a particular circumstance. Regardless of the type of valuation, the Greek Constitution (Article 17, paragraphs 2-5) clearly forbids estimation based on possible future projections. In this way, future externalities, positive or negative, deriving from the change of use are not incorporated. This contravenes the Pareto optimal resource distribution and even challenges the Caldor-Hicks compensation criterion, especially in cases of partial takings. We suggest valuation to include a best-case and a worst-case scenario for possible future values. A combination of them, e.g., the average, will be used to determine benefits and costs and the final level of compensation. The most important externality under consideration, especially in cases of land properties condemned for public large-scale constructions, such as environmental public utilities, should be the environmental effect. The internalisation of possible negative externalities should be internalised by the construction benefactor.
\end{abstract}

Keywords: valuation, property taking, Pareto optimum, environmental externalities

\section{Introduction}

The procedure for the selection process is called optimization or maximization. In the business world, almost all the decisions may be considered as optimization problems. The optimization can be applied not only to maximize profit and minimize the cost of production, the use of the optimal size, but also in the employment of the highest quantity of a productive factor. Optimization without constraints means that a business seeks to maximize the benefits or minimize costs without putting constraints on resources that will be used. The optimization effort can be not only one but several things simultaneously, so the problem becomes more complicated. There is a problem with optimization constraints when seeking to maximize utility or minimize the cost of an activity with the restriction that is certain pore size that can be placed (Carson \& Mitchell, 1993).

The individual seeks to maximize his/her own benefit, cares only for his/her private benefits and costs, and utterly is indifferent to the consequences of acts of other members of society. The relationship between risk and

Odysseas Kopsidas, Dr., Ph.D., Department of Civil Engineering, Technological Educational Institute of Thessaloniki, Thessaloniki, Greece.

Leonidas Fragkos-Livanios. Dr., Ph.D., Division of Natural Sciences and Applications, Hellenic Army Academy, Attiki, Greece.

Correspondence concerning this article should be addressed to. Odysseas Kopsidas, Department of Civil Engineering, Technological Educational Institute of Thessaloniki, 17th Km Thessaloniki-Sindos, Thessaloniki 57400, Greece. 
expected return is the key to whether or not to an investment. Often, projects or activities have external effects, which involve social costs or benefits, in addition to private. External influences, because they are internalized in market prices and create tension between market prices and social benefits or costs. With the economic analysis or cost-benefit analysis, it identified and quantified the benefits and costs of activity or policy, and considered whether it is appropriate and beneficial implementation of the whole economy and society (Flad, 1997).

\section{Implementation}

To properly place a cost-benefit analysis, all sizes should reflect the image of society. The various inputs and outputs that occur on a project from markets can function effectively or not. When markets function efficiently, the use of the purchase price is good approximation of the social cost. When you come from markets that not operate effectively, the price does not reflect the true social costs them. With the "Cost-Benefit Analysis (CBA)", all critical parameters problem attributed to a single base assessment, which facilitates decision-making process. The basis of evaluation is to compare benefits and costs. If the benefits are larger, then the project (or activity) is socially desirable (Hochman \& Ofek, 1979).

Otherwise, it is considered socially beneficial. "Weak" Treaty Pareto: A project or a policy measure is socially acceptable when improving the welfare of every member of society. "Strong" condition Pareto: A project or a policy measure is socially acceptable when ensure improved welfare even one person without reducing the welfare of another. The Pareto principle is based on individual conception of welfare, whereby the people regarded as the best exponents of their own prosperity through their options. He has limited use, since there is almost no action to improve. As someone while continuing to deteriorate the position of others. Not discussed concepts, such as social justice or income redistribution (Karadimitriou, 2013).

The search for suitable instruments or for the best possible combination of the use of command, control, and economic instruments nowadays constitutes one of the most complex points of discussion on environmental economics. The environmental reassessment of economic procedures and the change in production and consumption of non-conservation friendly models, which constitute the fixed position of the European Union and the OECD, could be achieved by using suitable economic instruments. We are focalising his present study on environmental taxes, the most well-known and widespread category of economic instruments, by studying the advantages and disadvantages of their enforcement (Karadimitriou, 2013).

Next, we will present the experience at an international level, focusing on their use as well as the consequences on international competitiveness. According to the first theorem of economic prosperity, under certain conditions, a competitive economy guarantees a Pareto-optimal economic outcome. In other words, a competitive market leads to allocations of resources to the property that any position cannot improve not worsen the position of another. This allocation is done automatically through the price mechanism, e.g., where there is a demand that the price goes up and when a bid price it falls. The adjustment of prices solves the problem of distribution of goods. The second fundamental theorem states that the competition of firms has the objective maximization of profits consumers. Therefore, it is necessary to have a central designer will decide who gets what in the economy. In fact, the free market can lead to great disparities that can be removed by state intervention (e.g., taxation). According to the criterion of a Pareto distribution, it is effective when there is no other way allocation to improve one's position without diminishing someone else.

The externalities or the external economies occur when a person acts or a business affect other people or companies when a company imposes a cost on others, but does not compensate, or end, when a company brings 
benefits in other businesses, but does not receive remuneration for providing this benefit. We can distinguish two types of externalities, public (e.g., air pollution, the water that affects the welfare of many people) and private (e.g., a person casts trash in the yard of neighbour). This movement affects the welfare of the neighbour and any other. The cases where the activity of an individual or business impose costs others refer to as negative externalities or external costs. When induced positive externality in the production of a commodity, the social costs production is less than the private cost. The optimal quantity of good "Q" optimum is greater than the equilibrium quantity "Q" market.

Notice that in both cases, either external charges or external economies, the price mechanism does not give enough information to the recipient of decisions. In one case, the values do not represent the actual cost and the other is not represent a real benefit. We say market failure. According to Pigou in his "The economics of Welfare", taxation is a effective tool for addressing the external charge. In the case, foreign economy given subsidy represents the real benefits of business. Unlike the Coase in his "The problem of social cost" where there is a way of supporting addressing externalities awarding property rights over natural resources. He argues that if the contaminant obtains a right of victims of pollution, then pollution will pay the first to stop or reduce the polluting activity. Unlike the pollutants to be able to benefit from the natural resource should compensate the victims, which have acquired the right to operate.

When there is a clearly defined system of property rights, the market mechanism will lead to an efficient allocation of resources. In environmental policy, the polluter (whether company, individual, or the State) pays applicable in several countries the world. This is automatically an incentive to reduce pollution at least at the level where the marginal cost of reducing pollution equals the marginal cost of damage causing this pollution. Also, many countries apply the system of subsidies for the pollution control. This suggests that property rights are particularly important in the formation of environmental policy. Residents should have rights property, the polluter or the victim worked (Coase, 1960). In theory, it places great emphasize on the importance of ownership of natural resources and to negotiate between those who pollute and those who suffer from pollution. One of the conclusions of $\mathrm{R}$. Coase was that under certain conditions, the creation of property rights can lead the parties that are on opposite sides to have interest in negotiating among themselves to find an agreed solution on the level pollution would be considered socially acceptable (Lee, McElheny, \& Gibbons, 2007).

The adoption sustainable development as a central policy choice, but as a principle of both international and European and domestic legal systems (especially after the revision of the Article 24 of the Greek Constitution) creates new standards for the role, nature, and function of environmental policy tools. In particular, the passage of regulatory approach to environmental protection, which was based mainly on the use of direct intervention on the strategic and integrated approach, requires an overall strategy for sustainable development. Main aim towards sustainable development is the environmental redefinition of economic processes and a fixed position of the European Union and Organisation for Economic Co-operation and Development (OECD) agreed at the World Johannesbur (McWilliams, 2011).

Environmental redefinition of economic processes and changing unsustainable patterns of production and consumption agreed at Johannesburg, cannot achieve with tools to intervene directly, but rather the use of economic tools. The same should be accepted and to solve the environmental problems the second generation, such as climate change, biodiversity loss, and soil erosion, as taking effective measures in this direction requires the use of other tools except those of direct intervention. The key feature of economic instruments is that the type of conduct which guides the operators of production processes associated with a particular economic advantage. 
The logic function consists, in particular to internalize partially or completely, of "externalities", i.e., the impact on the environment, which is secondary effects of production processes and consumption and which are not calculated as a cost to those who cause it. This is also an established position in economic theory. It should also be noted that all financial instruments not show the same degree of compatibility with the market mechanisms (e.g., permits emissions have the greatest degree of compatibility with respect to subsidies, which a minimum).

These tools provide economic incentives for environmental change behaviour either through direct changes in the levels of prices and costs through fees products, duties on carbon or on raw materials, or through indirect changes in prices or the cost through financial and fiscal instruments, such as direct subsidies, loans, or end through creating new markets for environmental good, such as tradable licenses, etc. The production and consumption of goods and services have resulted create adverse impacts on the environment. Starting thus with the principle "I live, so befoul" and realizing that one cannot speak for the elimination of pollution, the problem lies in "how much pollution." In other words, in what will be the "optimum" level of environmental pollution or environmental protection from pollution, based on various economic, technological, social, psychological, and other parameters that apply to a society in a given period (Klauer, Dingus, Neale, Sudweeks, \& Ramsey, 2006).

According to literature (McWilliams, 2011), environmental degradation may be defined in economic terms, as external costs. The internalisation of these costs occurs when polluters pay a tax or a fee. A tax or fee is defined as the payment for each unit pollution deposited and is attracted to the environment or any environmental unit destruction/degradation. The main economic reason for using taxes in environmental policy is the integration the costs of pollution and any other use of the environment on commodity prices and services produced by economic activities. Such costs are called "externalities" because they are side effects of economic activity and not part the prices paid by producers or consumers who are directly involved. When the externalities are not included in prices cause major market distortions encouraging activities that are costly to society even if the private benefits are important, the calculation of the economic value of externalities is not easy. For example, recent calculations show that the external environmental costs of road transport, such as increased costs resulting from air pollution, climate, and disturbance from noise, is quite large and growing. These 40 externalities cost the EU an average of about 5.5\% of Gross National Product (GDP). If you include the costs associated with accidents, costs are as high as $7.8 \%$ of GDP (EEA, 2000, Environmental Taxes: Recent Developments in Tools Integration). An environmental tax tries to incorporate these external costs on prices (internalising externalities), so that both social and private costs to come closer. The better prices allow the markets to work more efficiently, leading to a reallocation of resources under "fair and efficient" prices through the redistribution of costs. Environmental taxes also help in implementing the principle "the polluter pays", after facing those who cause pollution to the full costs of polluting their activity. In practice, there is little or no agreed data on the economic costs of externalities or their distribution and therefore the people making policies determine the price environmental taxes on those levels that they believe will achieve their goals their policy (McWilliams, 2011).

The impact of environmental taxes on competitiveness is an issue which is constantly on the agenda of discussions. The potential adverse effects on international competitiveness concern to designers of environmental policy when considering their application in energy and other products related to environmental problems. Some factors affecting the efficiency of environmental policy and effects on international trade are: the size of its economy and its influence on pricing internationally, the homogeneity or diversity of products produced in areas affected from taxation, the size of import substitution and innovation, mobility of production factors, the trade agreements between countries and as they affect the possibility of tax adjustment and other measures to reduce 
adjustment costs, and the introduction of similar measures in other. Initially, the solution of environmental problems was used in system direct control (strategy command and control). The inability of the system for control and imposition of rules by the State in conjunction with the economic inefficiency characterizing the system cost of pollution control, led to the shift environmental policy, adopting economic tools to solve them. According to experience so far, financial tools, can under certain circumstances act as flexible, efficient, and effective mechanisms to achieve environmental objectives (Loures, 2015).

\section{Concluding Remarks}

In this analysis, it is considered the natural environment as a public good and environmental pollution as an external economy fails the price mechanism to internalize. In all three cases, the approach of foreign trade was with the "willingness to pay (WTP)" method and calculated the external costs generated by the degradation of the environment from the responses of respondents in monetary units. Respondents answered without knowing it was the environment to its original condition and not expect it to return to its original form. The quality of the clean environment and therefore the valuation of foreign economic burden are caused by the contamination with personal criteria and with personal endorsement of the value of that public good. In the case of archaeological monuments, residents have built their buildings. In case of lakes, respondents have developed an urban way of life around the lakes. In the case of industrial units, residents have supported throughout the local economy on them. The initial state of the environment is unknown and undefined. Also, the natural environment that is altering the original state cannot be determined. Human works and buildings create new values in the region and therefore the external costs can be measured only with the expected quality of the environment and is not lost. Allowances, taxation, and value of land use are calculated solely on the expected image of the landscape.

Therefore, the Pareto optimal socio-economic lines status is defined according to the new form of environment created after the regeneration of areas and not according to the initial state of the environment. Also in Kaldor, compensation should be determined based on the economic valuation of public goods by their own people, who judge based on expectations rather than on the past. The expected form natural environment varies from respondent to respondent and its approach to social welfare units can only be done through alternative scenarios best and worst scenario. In any case, the society wants to reach the minimum point of the charge received from the pollution and what can be achieved by the "invisible hand", but the regulation and government intervention. History has shown that the charge received by the society because of pollution varies with the socio-economic status of citizens. The more low-income residents who are more elastic is the loss of the natural environment. The elasticity of citizens deprived of the physical environment or not is measurable size.

\section{References}

Carson, R. T., \& Mitchell, R. C. (1993). The value of clean water: The public's willingness to pay for boatable, fishable, and swimmable quality water. Water Resources Research, 29(7), 2445-2454.

Flad, H. K. (1997). Country clutter: Visual pollution and the rural roadscape. Annals of the American Academy of Political and Social Science, 533, 123-125.

Hochman, O., \& Ofek, H. (1979). A theory of the behavior of municipal governments: The case of internalizing pollution externalities. Journal of Urban Economics, 6(4), 416-431.

Karadimitriou, N. (2013). Planning policy, sustainability and housebuilder practices: the move into (and out of?) the redevelopment of previously developed land. Progress in Planning, 82, 1-41. 
Klauer, S. G., Dingus, T. A., Neale, V. L., Sudweeks, J. D., \& Ramsey, D. J (2006). The impact of driver inattention on near-crash/crash risk: An analysis using the 100-car Naturalistic Driving Study data. Report DOT HS 810 594, National Highway Traffic Safety Administration, Washington DC, USA.

Lee, S. E., McElheny, M. J., \& Gibbons, R. (2007). Driver performance and digital billboards: Final report prepared for the Foundation for Outdoor Advertising Research and Education. Virginia Tech Transportation Institute, Center for Automotive Safety Research, Blacksburg, VA, USA.

Loures, L. (2015). Post-industrial landscapes as drivers for urban redevelopment: Public versus expert perspectives towards the benefits and barriers of the reuse of post-industrial sites in urban areas. Habitat International. Special Issue: Exploratory Spatial Analysis of Urban Habitats, 45(2), 72-81.

McWilliams, A. (2011). Creating and capturing value: Strategic corporate social responsibility, resource-based theory, and sustainable competitive advantage. Journal of Management, 37(5), 1480-1495. 